\title{
De rios e de mar no De Antiquitatibus Lusitaniae de André de Resende
} On rivers and the sea in De Antiquitatibus Lusitaniae by André de Resende

\author{
Inês de OrNellas e Castro ${ }^{1}$
}

Resumo: O De Antiquitatibus Lusitaniae (1593), de André de Resende, uma das obras mais notáveis do humanismo português, revela a erudição de um antiquário pioneiro nos campos da Arqueologia e da Epigrafia e com profundo domínio dos textos clássicos, filosóficos, teológicos e bíblicos. Investigou de modo original como nasceu e cresceu Portugal. Ao situar a história no espaço, foi rigoroso na Geografia. Nas referências dispersas sobre agricultura e pecuária, mas sobretudo no Segundo Livro, dedicado aos rios e à respectiva fauna piscícola, em que incide a nossa reflexão, revela um conhecimento implícito das teorias higienistas do seu tempo, manifesto na interdependência entre meio ambiente, homem e alimento. 0 confronto de obras de arte médica com uma leitura atenta no original permitiu encontrar indícios de um discurso de matriz humoral.

Palavras-Chaves: André de Resende; De Antiquitatibus Lusitaniae; alimentação; ictiologia.

\begin{abstract}
André de Resende's De Antiquitatibus Lusitaniae (1593), one of the most notable works of Portuguese Humanism, reveals the erudition of an antiquarian, pioneer in Archaeology and Epigraphy with a deep domain of classical, philosophical, theological and Biblical texts. He investigated in an original way how Portugal had born and grew. When pointing out history in the space, he was rigorous in Geography. In the dispersed references on agriculture and cattle, and especially in the 2end book dedicated to the rivers and respective fish fauna, the focus of our reflection, he discloses to an implicit knowledge of his own time hygienists theories, revealed in the interdependence between environment, man and food. The original Latin text confrontation with medical works allowed us to find indications of an humoural matrix speech.
\end{abstract}

Keywords: André de Resende; De Antiquitatibus Lusitaniae; food; ichtyologie.

${ }^{1}$ DIAITA/IELT-NOVA FCSH. A autora escreve de acordo com a antiga ortografia. 
Alterum alosarum genus [...] sabogarum uel sabellarum, strigosius insipidius que est, praeterquam Maio mense, tunc enim aliquam in eduliis habent gratiam, uerum ita, ut recentes a flumine prunis in craticula tostae, pretoselini pultario ex piperi ac mali Medici succo condiantur.

(André de Resende, De Antiquitatibus Lusitaniae, 2: 67-68)

Não se enganará quem reconhecer na epígrafe uma receita para confeccionar um género específico de sável. Ainda que uma introdução nestes termos possa parecer ex abrupto, considerámos que seria a melhor forma de aliciar o leitor. Na verdade, foi este breve excerto, mero pormenor num texto de tamanha riqueza, permeável a uma multiplicidade de exegeses, que estimulou a nossa curiosidade e propiciou a reflexão que pretendemos fazer ao longo deste artigo, centrada no modelo de discurso científico subjacente aos excursos do que hoje consideramos história cultural da alimentação. Exactamente por isso, embora tenhamos utilizado a melhor edição do De Antiquitatibus Lusitaniae, com uma brilhante tradução comentada de Raul Miguel Rosado Fernandes e estabelecimento de texto latino por Sebastião Tavares de Pinho, que constitui o vol. III dos Portugaliae Monumenta Neolatina, que seguiremos, preferimos adoptar uma versão literal nossa (nesses casos assinalada), sempre que esta servir com maior rigor o objectivo estrito deste trabalho, ainda que esta peque por não ser tão elegante como a do nosso citado Mestre. Convém acrescentar que todos os outros excertos de opúsculos ou tratados neolatinos serão sempre traduções da nossa autoria.

Eis a tradução, nossa, que propositadamente preferimos apresentar no corpo do texto, ao invés de colocá-la em nota: «Existe um outro género de sável, [...] as sabogas ou savelhas, mais magro e mais insípido salvo no mês de Maio, adquirem então, com efeito, um sabor algo agradável como alimentos, desde que assadas na grelha sobre as brasas, acabadas de sair do rio, sejam adubadas com salsa e pimenta e até sumo de limão [misturados] numa tacinha.»

Trata-se, com efeito, da única receita de Resende no seu eruditíssimo De Antiquitatibus Lusitaniae [As Antiguidades da Lusitânia], de editação póstuma, 1593, 20 anos após o seu falecimento. Os quatro livros ${ }^{2}$, nenhum com tí-

\footnotetext{
2 Apresentamos de modo muito sucinto, para que se compreenda a temática do Segundo Livro, o conteúdo dos outros três. O Primeiro Livro é dedicado à discussão etimológica do topónimo Lusitânia. É aqui que encontramos a patriótica lenda de Luso alicerçada na interpretação da História natural, 3, 1, 8 de Plínio-o-Velho. Segue a explicitação dos limites territoriais da Lusitânia na Antiguidade, posto não corresponderem às fronteiras de Portugal à sua época, e, só depois, se dedica à descrição de todos os povos que a habitaram, com enfoque nos Lusitanos, terminando com larga explanação sobre o relevo. No Terceiro Livro centra-se nos povos que dominaram a Lusitânia, desde os Lusitanos, o que lhe permite criar a lenda de Viriato, passando pelos Cartagineses, Gregos (que não dominaram, mas com os quais teria havido relações comerciais), Iberos, Celtas, Fenícios e Tírios. Há um capítulo especial para os Godos, terminando o livro com um capítulo sobre as vias militares romanas, tendo por fonte o Itinerário de Antonino Pio. O Quarto Livro ocupa-se das cidades e demais localidades da Lusitânia, da etimologia dos topónimos, da sua história, dos monumentos e de vários aspectos geo-
} 
tulo original ou aposto pelo editor, publicados por Diogo Mendes de Vasconcelos, pretendiam ser parte de um opus magnum inacabado, composto por 10. Trata-se de uma história enciclopédica sobre como nasceu e cresceu Portugal, desde os alvores da presença romana na região da península configurada pelos limites do que viria a ser a pátria $\operatorname{lusa}^{3}$ até ao Renascimento. Só nos últimos quatro anos de vida se dedicara a compô-la, conquanto fosse fruto de investigações compiladas ao longo de cerca de 50 anos, segundo testemunho do seu editor e amigo, que, com provável exagero e evidente auto-elogio, evidencia estar ali muito do seu próprio labor para poder dar à estampa o De Antiquitatibus. Talvez algumas partes se afigurassem confusas, mas em todos os livros verificamos existir uma grande coerência.

O leitor dos nossos dias pode considerar que as digressões, de nítida influência clássica, em que se pode vislumbrar uma exposição próxima da construção da História natural de Plínio-o-Velho, uma das suas fontes para a Hispânia, constituem um entrave ao fluir do texto. Mas são estes excursos de teor literalmente enciclopédico - gr. enkyklios, o que abrange um círculo, e paideia, educação -,

gráficos, centrando-se no Sul, que melhor conhecia e onde fez trabalho arqueológico e amplo estudo epigráfico (com algumas fraudes para ilustrar as suas teses, mas no geral correctas). Do Quinto Livro deixou apenas 25 linhas, pelo que não foram editadas.

${ }^{3}$ A Lusitânia romana teve duas divisões, uma até 26 a.C. e outra posterior. preconizados pelos humanistas, que assim exibiam a sua erudição, que nos permitem encontrar algumas pérolas. A mais extensa é uma entusiástica «disquisitio», investigação, de 10 páginas dedicada ao esturjão, inserida exactamente no Segundo Livro, aquele de que mais nos ocuparemos. É exclusivamente dedicado à descrição geofísica dos rios, de Sul para Norte - orientação seguida pelo autor, a que não será estranho ser natural de Évora -, que desaguam em Portugal e à respectiva fauna piscícola. Como o próprio refere na página 78, pois citaremos sempre a partir da editio princeps, existem mais rios conhecidos, «No entanto, visto que se lançam noutros maiores e não desaguam no mar em leitos próprios, ou foram desconhecidos dos geógrafos ou omitidos. Referirei alguns deles dignos de chegarem ao conhecimento dos nossos compatriotas». André de Resende tem por interlocutor directo o leitor erudito de toda a Europa pensante, que domina o Latim e as fontes por ele usadas, mas é, todavia, compelido a ter presente que os seus conterrâneos não the perdoariam a ausência de outros importantes cursos fluviais. Os rios em apreço abarcam não só os mencionados amiúde pelos Gregos e Latinos, pois «tanta claritas est» $(2,54)$, tanta é a celebridade, diz explicitamente sobre o Guadiana, o Tejo, o Mondego, o Ave, o Lima e o Minho, mas outros, pertinentes do ponto de vista geográfico, domínio científico em que foi pioneiro entre nós. 
Poder-se-ia pensar que, num livro sobre rios, a matéria ictiológica cingir-se-ia à fluvial, mas assim não acontece. A fertilidade alimentar da Lusitânia, louvada neste livro em particular, mas a que por vezes alude no Primeiro e no Quarto, passa igualmente pelo mar. Embora este pouco espaço ocupe na totalidade do De Antiquitatibus, precisamos de ter em conta que grande parte dos peixes de rio são «fluviales migrantes», como os designavam os Antigos: uns anádromos, vêm do mar e sobem os rios para desovar, como o sável ou o esturjão; outros catádromos, desenvolvem-se nos rios, mas nascem no oceano - é o caso da enguia, cujas larvas nadam grandes distâncias até chegarem aos rios.

Se de todos os rios e respectiva foz ou delta pretende enumerar a fauna, como a diversidade à época não é muita - recordemos que várias espécies foram posteriormente introduzidas -, e o autor pouco aflorou as espécies especificamente pelágicas, mais do que a variedade salienta a quantidade ou o tamanho dos espécimes, característica que poderemos aproveitar para a nossa exegese, mas, de facto, a abundância é, pelo menos na aparência, um dos principais topoi das descrições da Lusitânia $(2,80)$ : «quam fecunda, fertilis, ac felix haec regio de qua agimus sempre habita fuerit» [a região que tratamos sempre foi considerada como mui fecunda, fértil e privilegiada]. Assim o pediria um projecto de cunho patriótico, destinado a salientar a portugalidade numa Hispania que além-fronteiras parecia una, tanto mais que a Castela nem sempre interessara distinguir o que era especificamente luso.

Seguindo os cânones europeus da época, concilia os conhecimentos sobre História, Linguística, Geografia e Ciências Naturais com o esforço de compilação próprio de um antiquário, à maneira renascentista, e de um arqueólogo, que, munido das suas alfaias, vai pelos campos pondo a descoberto inscrições. Pela sua mão falaram, pela primeira vez, muitas pedras e, se em alguns momentos se descobre uma fraude, na maioria das vezes fala a verdade,como reconhecem os estudos epigráficos da actualidade (Encarnação, 1991: 193-221). Vivia-se o tempo da redescoberta da Antiguidade, do manuseamento de manuscritos recém-descobertos ou lidos à luz de um novo entendimento, como os textos gregos dados à estampa com minucia nas edições aldinas, da troca de correspondência entre eruditos unidos numa mesma língua de cultura, o Latim, que faziam circular factos e ideias, em que se enchiam gabinetes privados com colecções de inscrições e curiosidades, ora para estudo, ora para ostentação, gérmen da ideia de museu que o século XIX traria. É, pois, este o mundo do muito viajado humanista André de Resende.

Qual é, então, a matriz do seu discurso quando faz incursões na esfera alimentar? Os tratados técnicos com descrições de relevo, clima e outras questões de natureza geográfica abundavam desde a Antiguidade, mas, ao discorrer sobre aspectos alimentares piscícolas ou de 
outra ordem e ao sublinhar as qualidades dos produtos, o Autor sabe que só pode comunicar com os seus potenciais interlocutores, em Latim, munindo-se de linguagem passível de ser compreendida por todos. Em nosso entender, só existe uma universalmente aceite pela intelligentsia do seu tempo, cujas categorias validadas e respectivo léxico permitem, por exemplo, elogiar um sabor sem subjectividade: a higienista. $O$ decoro viril passa pela matéria exposta; a escrita masculina com receituário alimentar surge sempre num enquadramento científico, geralmente de arte médica, com um discurso próprio. Será esta a nossa linha de reflexão: verificar qual o critério adoptado por André de Resende para proceder a um levantamento das espécies - porque escolhe umas e não outras, se trabalha não apenas com fontes documentais, mas baseado na experiência - e até que ponto a descrição se insere num discurso a que está subjacente uma filiação dietética. A nossa metodologia passa em primeiro lugar, como atrás afirmámos, por nos socorrermos do original latino, analisando o léxico, dando especial ênfase aos vocábulos escolhidos, partindo do princípio de que, não estando a estética apartada, correspondem a uma formulação em consonância com a teoria humoral, a que nenhum humanista contemporâneo seria estranho. Pretendemos abonar os argumentos com autores anteriores, contemporâneos ou ligeiramente posteriores, mas cujas posições estejam em consonância com a matéria em apreço. Não é por acaso que entre as suas fontes se incluem, além dos clássicos, dois dos maiores ictiólogos da época, os médicos Paulo Jóvio (1483-1552) e Guillaume Rondolet (1517-1566). Tentaremos tornar perceptível o que aos olhos dos demais se tem mantido discreto.

Poder-nos-ão objectar que não é a primeira vez que na obra deste humanista surge um excurso com uma receita, como a longa digressio em 22 versos no Genethliacon, o poema dedicado ao nascimento do príncipe D. Manuel, filho de D. Catarina e D. João III. Explica, em pormenor, como se confeccionam uns pastéis, os farctilia Lusitana, com o objectivo de dar a conhecer aos seus pares da Europa uma maravilha da doçaria portuguesa, «como nenhuma outra se pode encontrar em toda a terra» ${ }^{4}$. Esta é, porém, uma receita do estrito âmbito da culinária, uma liberdade permitida num discurso laudatório, em que se pretende deleitar.

Está implícita em determinados passos do De Antiquitatibus, nomeadamente no modo de tratar a relação entre o homem, o alimento e o meio físico, uma forma mentis a que não é alheio o discurso de matriz higienista. Ninguém vive apartado do seu tempo, e Resende, cuja curiosidade o abalançou a interessar-se pelo saber como um todo, conhecia as teorias da arte médica que então vigoravam e faziam parte dos conhecimentos práticos de toda

\footnotetext{
${ }^{4}$ Vide Genethliacon, 1533, fls. DIII r-v, 631-653.
} 
uma elite. Embora não seja o nosso propósito discorrer sobre a teoria humoral hipocrático-galénica revisitada ao longo dos séculos - seria descabido pensar que se manteve inalterada, provam-no a quantidade de tratados intitulados «Comentário» à obra desta ou daquela autoridade -, convém salientar, de forma breve, alguns aspectos passíveis de ler sob outra lente certas descrições do Autor. $\mathrm{O}$ ar e o meio ambiente interagem com o indivíduo e com todos os seres vivos que este consome. Este par, que podemos reduzir a clima, constitui uma das chamadas «seis coisas não naturais», isto é, um dos seis factores externos ao homem que contribuem para the proporcionar saúde. Uma vez que se acreditava que se agia de fora para dentro, o médico teria em conta todas as causas exteriores ao prescrever um regime de vida adequado ao seu paciente, sobretudo medidas preventivas, pois ao verdadeiro iatra competia,em primeiro lugar, manter e, em segundo, tratar ou curar, caso ocorresse um desequilíbrio. Destacamos alguns passos do Segundo Livro em que se destaca a importância da relação com o meio:

Graças à sua água e ao pasto, de tal modo pela própria força interior se desenvolve o gado, que na Hispânia deve ser atribuído o primeiro prémio de corpulência às manadas e bois da região do Guadiana. Embora o rio seja muito rico em peixe, recomendam-se mais pelo tamanho do que pela delicadeza do paladar. (2: 54-55)
Por delicadeza de paladar, no original «iuf cunditate saporibus», entenda-se, segundo a nossa interpretação, pelo prazer dos sabores. Pode parecer inócuo, todavia, considerava-se que o prazer do sabor remetia para a boa qualidade do alimento. $O$ sabor agradável participava do conceito dietético de bonus cibus ou cibus euchymus, alimento com sucos de boa qualidade. 0 paladar não é uma mera apreciação subjectiva:
Na medicina Antiga e na pré-moderna, porém, o gosto é um sentido fundamental. 0 gosto, um dos dois sentidos químicos, uma vez que pela sensibilidade chega à substância, é, di- ríamos, bastante cognitivo. Permite conhecer a essência do objecto, a sua substância, através da incorporação literal: provamos, degus- tamos ou comemos. Com o gosto ou paladar verificamos as quatro qualidades - quente, frio, seco e húmido - patentes nos sabores do objecto (que não é um acidente mas subs- tância, se usarmos uma terminologia aristoté- lica). Para o médico o gosto apresenta-se, pois, como uma categoria fundamental para chegar ao diagnóstico. (Castro, 2018: 326)

Noutro momento, ao fazer o elogio da fertilidade de toda a Lusitânia $(2,80)$, afirma: «Considero que é útil dissertar aqui sobre o estado actual desta província, seu agradável clima e abundância e produtividade de frutos de toda a espécie». E reforça com a citação de Ateneu (Ateneu, 8: 331, b-c) «ali, graças à óptima temperatura do ambiente [aeris temperiem], os 
animais e as gentes são fecundos e [...] jamais faltam produtos da terra naquela região.»

Se partirmos do princípio de que, no léxico médico, «temperies» consiste na justa proporção de humores ou qualidades, ver-se-á que Resende avalia o meio físico com critérios humorais, sendo passível, sem jamais tirar mérito à tradução apresentada, verter por «graças à qualidade adequada do ar». Na verdade, temos tendência a ler os textos de acordo com a formação que fomos adquirindo.

Outro par importante das «seis coisas não naturais» é configurado por comida e bebida, ou seja, a dietética. $\mathrm{O}$ homem, como todos os seres vivos, partilha das mesmas qualidades dos quatro elementos - a água fria e húmida; a terra fria e seca; o ar quente e húmido e o fogo quente e seco - que compõem o macrocosmo. $\mathrm{Em}$ função dos humores predominantes, um indivíduo, tal como os demais seres vivos, poderá apresentar um temperamento fleumático (a pituíta é fria e húmida), melancólico (a bílis negra é fria e seca), sanguíneo (o sangue é quente e húmido) ou colérico (a bílis amarela é quente e seca). A cocção operada no interior do organismo modifica estas massas líquidas, os humores. Assim sendo, a saúde não será mais do que o justo equilíbrio dos humores, sendo indispensável consumir alimentos que contribuam para manter ou reparar a almejada temperança. Os produtos a consumir deveriam ser escolhidos em função do temperamento de cada indivíduo, pois o que para uns seria benéfico, para outros mostrar-se-ia nocivo.

No caso dos produtos piscícolas, coloca-se um problema: todos os peixes frescos eram considerados frios e húmidos, tal como o elemento água, cujas qualidades partilhavam. Pelo facto, eram desaconselháveis, sobretudo os pelágicos, excepto para quem tivesse um estômago quente, como seria o caso dos indivíduos de temperamento colérico, quente e seco. 0 tipo de suco predominante na fauna piscícola não os tornava um alimento adequado para os regimes, quer de saudáveis quer de doentes. Com efeito, as qualidades frio e quente eram consideradas activas, sendo o húmido e o seco as qualidades passivas. A manifestação mais evidente de doença seria gerada pelas qualidades activas, o que ainda hoje é perceptível, porque as febres, outrora consideradas doença, são actualmente um sintoma de alteração patológica. 0 consumo dos peixes deveria, por isso, obedecer a critérios específicos, e os mesmos deveriam ser cozinhados da forma menos prejudicial. Em primeiro, a frescura, o mais frescos possível, como o sável da nossa receita; em segundo lugar, optar-se-ia pela técnica de confecção adequada: cozidos para perderem as viscosidades ou «malitia», como se acreditava, ou assados, mas nunca fritos. Por último, em caso de necessidade, o temperamento do peixe corrigir-se-ia com um molho prescrito pelo médico. Encontramos bastantes indicações de molhos nas obras de medicina: 
Exemplo disso é o pequeno manuscrito do século XIV Opuculum de saporibus, Opúsculo sobre os sabores, de Magnino de Milão ${ }^{5}$ composto por três fólios ${ }^{6}$ repletos de considerações sobre o papel dos molhos na alimentação e com muitas receitas, observando quais os melhores condimentos para os vários tipos de alimentos. Foi escrito por um cozinheiro? Não, um médico, apostado em dissertar sobre a importância dos sabores sem perder a sua autoridade. Embora, no início do texto, considere que as delícias que conferem sabores, ou seja os temperos, tenham sido criados para volúpia dos gulosos e não por uma necessidade para a saúde ${ }^{7}$, a verdade é que lhes dá bastante ênfase. Recomenda o consumo destes em pouca quantidade, considera-os como medicamentos na alimentação das pessoas saudáveis ${ }^{8}$, mas reconhece-lhes qualidades para corrigir ou, pelo menos, suavizar a malignidade (malitia) das comidas, de modo a tornar mais deleitável o apetite e ajudar a digestão, assim como auxiliar a retenção ou a expulsão no organismo. (Castro, 2018: 329-330)

5 Também conhecido como Magninus Mediolanensis, conforme consta nas primeiras edições do Regimen sanitatis, escrito c. 1331, de que é autor.

${ }^{6}$ Biblioteca Nazionale de Nápoles: MS. VIII. D. 35, fl. 52r, col. 2-53", col. 1.

7 «Saporum delectamenta propter voluptatem magis quam propter sanitatem a gulosis fuerunt primitus adinventa non cum sint multum necessaria in sanitatis regimine ymmo quod plus est interdum inferunt nocumen.» (Opuculum de saporibus, fl. $52 r)$.

${ }^{8}$ «Amplius sapores ut per plurimum sapiunt naturam medicinalium que in regimine sanorum a sapientibus denegantur debet enim conservatio sanitatis abstinere ab omni medicinali.» (Opuculum de saporibus, fl. 52r).
Haveria, contudo, uns peixes mais aconselháveis do que outros, e os tempos de jejum do calendário litúrgico obrigavam ao seu consumo. Um excerto do tratado seiscentista de Fernão Solis da Fonseca no seu Regimento para conservar a vida e saúde, escrito em estilo dialógico, é esclarecedor. Um paciente, padecendo de gota - ou podagra, doença frequente entre os abastados que costumavam comer com frequência carne de juvenis, sendo, por isso, propensos a ganhar temperamento húmido -, perguntara se o pescado era em geral bom mantimento. Tendo recebido por resposta que todo o peixe é prejudicial, sendo os mais sadios, segundo Hipócrates, os de rocha, chega a esta conclusão: «Do peixe ser fraco mantimento, nam quero eu milhor argumento que a Igreja Catholica, a qual ordenou as quaresmas, e dias de jejum, de peixe, para fraqueza e penitencia.» (apud Pina, 1965: 14).

Os tratados médicos dividiam a fauna fluvial e marítima em quatro categorias, segundo a sua qualidade para a saúde, que denominavam bonitas. Numa obra de 1636, o De qualitatibus alimentorum, quae humani corporis nutritione sunt apta [Sobre as qualidades dos alimentos que são adequados à nutrição do corpo humano], de André António de Castro, encontramos muito bem exposto, no tratado 4, «Sobre os peixes», 0 6. ${ }^{\circ}$ capítulo, «De piscibus in particulari», dedip cado a classificar toda a fauna marítima portuguesa segundo a «bonitas» atribuída. Embora a obra bromatológica deste médico seja posterior, a forma mentis e o saber explicitamente 
galénico compilado - bastaria o título da obra De facultatitibus alimentorum para reconhecer a filiação - pouco diferem dos do tempo de Resende. A principal diferença entre a fauna marítima, nome mais apropriado porque até os cágados estão incluídos nas reflexões, ret side no habitat que condiciona a agitação das águas e o tipo de alimentos que consome, daí o tamanho, a febra mole ou dura, a capacidade de cozedura no estômago e o potencial nutritivo. Na 1. ${ }^{\text {a }}$ categoria, «primum locum bonitas», estão os peixes saxáteis ou petrosos, isto é, de rocha, que não são viscosos nem gordos (fls. 224v-226r); na 2. a estão sobretudo peixes das zonas costeiras mais batidas por ventos e alguns do mar alto, onde os ventos thes retiram a humidade considerada nociva, assim como as ovas, absolutamente proibidas em dietas para enfermos (fls. 226r-226v); na 3. a estão os peixes que apresentam suco vicioso e são de digestão difícil, incluem-se vários peixes de couro, como a enguia, o cação, a moreia, e outros demasiado gordos, os que na Antiguidade serviam para produzir os famosos molhos de peixe como o garum, tais como a sardinha ou o atum, além de moluscos (fls. 226v-227r); na 4. ${ }^{a}$ categoria encontramos os crustáceos e os testáceos, ou seja, mariscos em geral, além do cágado, da rã e da tartaruga, pois todos produzem um suco gordo e indigesto (fls. $227 r-228 r)$.

Apresentamos um quadro com o levantamento de todas as espécies referenciadas na obra. Considerámos mais adequado, mesmo havendo lugar a repetições, distribuí-las pelos rios, pela ordem em que estes são mencionados, e, do mesmo modo, citar as espécies exactamente pela ordem de ocorrência. Numa das colunas colocámos, à frente de cada espécie, o número da categoria a que pertencem, de acordo com a taxinomia bromatológica supracitada. 0 esturjão não é citado em nenhuma das categorias do tratado de André António de Castro, muito possivelmente por já não ser tão frequente em 1636 . Consideramos, todavia, o facto estranho, pois apareceram exemplares em Portugal até ao século XIX. Atendendo às suas características, muito embora fosse uma iguaria, seríamos conduzidos a inclui-lo na 2. ${ }^{\text {a }}$ categoria. As variedades de acipenserídeos existentes entre nós - e há mais do que uma vintena de espécies no mundo, algumas das quais extintas - pouco se distanciam dos litorais, pois alimentam-se nos deltas e nos estuários, onde, com seu «nariz» achatado, sugam moluscos, crustáceos e pequenos peixes junto ao solo, por não possuírem dentes; sobem depois os rios para desovar. 
Espécie piscícola

Nome latino

Categoria

Rio

\begin{tabular}{|c|c|c|c|}
\hline Sável & Alosa & $2 .^{a}$ & Guadiana \\
\hline Lampreia & Lampetra & $3 .^{a}$ & \\
\hline Mustela & $\begin{array}{c}\text { Mustela ou } \\
\text { Murena fluuialis }\end{array}$ & $3 .^{a}$ & \\
\hline Esturjão/asturjão & $\begin{array}{c}\text { Acipencer/sturio } \\
\text { Asturio }\end{array}$ & & \\
\hline Mugem & Mugilis & $2 .^{a}$ & Sado \\
\hline Mugem cabeçudo/tainha & $\begin{array}{l}\text { Mugil cephalus } \\
\text { (Mugil cephalus) }\end{array}$ & $2 .^{a}$ & \\
\hline $\begin{array}{c}\text { Mugem beiçudo/ } \\
\text { tainha-liça }\end{array}$ & $\begin{array}{c}\text { Mugil labio } \\
\text { (Chelon labrosus) }\end{array}$ & $2 .^{a}$ & \\
\hline Barbo & Barbus & $2 .^{a}$ & \\
\hline Enguia & Anguillae & $3 .^{a}$ & \\
\hline Boga & Boca & $2 .^{a}$ & \\
\hline \multicolumn{4}{|l|}{ Outros peixes menores } \\
\hline Camarão & Cammarus & $4 .^{a}$ & \\
\hline Moluscos vários & Pectines & $4 .^{a}$ & \\
\hline Lampreia (rara) & Lampetra & $3 .^{a}$ & \\
\hline Sável & Alosa & $2 .^{a}$ & Tejo \\
\hline Saboga (var. sável) & Saboca & $2 .^{a}$ & \\
\hline Sabela/savelha (var. sável) & Sabella & $2 .^{a}$ & \\
\hline Lampreia (rara) & Lampetra & $3 .^{a}$ & \\
\hline Solho aqui porco-marinho & Suillus & $1 .^{a}$ & \\
\hline Sável & Alosa & $2 .^{a}$ & Mondego, Ceira e Vouga \\
\hline Lampreia & Lampetra & $3 .^{a}$ & \\
\hline Truta & Trocta & $1 .^{a}$ & \\
\hline Sável (grande) & Alosa & $2 .^{a}$ & Douro \\
\hline Lampreia & Lampetra & $3 .^{a}$ & Sobretudo São João da Pesqueira \\
\hline Truta & Trocta & $1 .^{a}$ & \\
\hline Salmão & Salmo & $1 .^{a}$ & \\
\hline Esturjão (raro) & Asturio & & \\
\hline Esturjão (os maiores) & Asturio & & Rios brácaros e rio Minho \\
\hline Lampreia & Lampetra & $3 .^{a}$ & \\
\hline Sável & Alosa & $2 .^{a}$ & \\
\hline Truta & Trocta & $1 .^{a}$ & \\
\hline Truta assalmonada & Troctasalmo & $1 .^{a}$ & \\
\hline Truta-marisca & Iridis & $1 .^{a}$ & \\
\hline Salmão & Salmo & $1 .^{a}$ & Lima \\
\hline Esturjão (menor) & Suillus/asturio & & \\
\hline Sável & Alosa & $2 .^{a}$ & Sorraia \\
\hline
\end{tabular}

Quadro com as espécies piscícolas classificadas e distribuídas pelos rios. 
Sabemos, porém, que, em Portugal, o peixe fluvial desempenhava uma função importante na alimentação dos mais desfavorecidos, a quem tais hierarquias ictiológicas pouco importavam, havendo queixas das populações quando os rios eram coutados, posto serem uma fonte de proteína importante:

O peixe foi sobretudo uma riqueza para as populações costeiras e para as que viviam em terras atravessadas por cursos de água, que se dedicavam à pesca como complemento das restantes actividades. 0 consumo de espécies de água doce e salgada, obtidas directamente ou já sujeitas a aquisição nos mercados, contribuiu para alimentar as populações sempre carentes de uma alimentação equilibrada. (Braga, 2015: 63)

\section{Encontramos no De Antiquitatibus 14 espécies} piscícolas, a que podemos acrescentar ainda 2 variedades de sável e 2 de mugem. Os critérios de valorização são, por ordem decrescente, a quantidade, o tamanho, o sabor e a qualidade/salubridade. Comecemos pelo fertilíssimo Guadiana (2, 54-65), o primeiro deste Segundo Livro, sobre o qual atrás discorremos em nome do prazer dos sabores. Desfilam aqui os sáveis e as lampreias, também denominadas moreias fluviais por Tertuliano ${ }^{9}$ ou mustelas. Será, todavia, o esturjão a suscitar maior interesse, matéria a gerar então debate entre os médicos, como o próprio sublinha, ocu-

${ }^{9}$ Tertuliano, De pallio, 5, 6: 68-70. pando a «disquisitio» um total de 10 páginas (55-65). Descreve a morfologia e o habitat do esturjão, sempre alicerçado nas citações das autoridades clássicas e dos seus contemporâneos Jóvio e Rondolet. Resende pretende que se adopte patrioticamente o ictiónimo «asturjão» por este ser abundante e de grande porte no rio Minho, para onde corre vindo das Astúrias, o que, aliás, havia sido proposto pelo bispo Miguel da Silva ao Papa Clemente VII. O mais interessante é, após tanta discussão em torno dos diferentes ictiónimos e das suas etimologias, nem todas hoje aceites, concluir ser o esturjão, do germânico «sturio», correspondente ao já há muito conhecido «soilho» ou «solho» de terras lusas, fazendo derivar a etimologia do Latim «suillum», porquinho, dada a morfologia da boca.

De entre a profusão de espécies do Sado (2, 65-66), sublinha o «egregio sapore», o excelente paladar, das enguias. O Tejo $(2,66-70)$ proporciona-lhe o elogio das lezírias férteis em trigo, cevada, milho-miúdo e belas vinhas, além das boas pastagens. 0 tópico da abundância ganha peso na admirável fecundidade em ostras e peixe. Mas ao sável atribui outras qualidades: «Entre os peixes do Tejo obtêm os sáveis a primeira categoria, não só pela boa qualidade [bonitatem] mas também pela abundância» (tradução nossa). Na verdade, o sável pescado no rio é considerado o de melhor qualidade por não ser seco como o do mar, tendo perdido a acrimónia e ganhado, por isso, melhor paladar. 
No aurífero e navegável Mondego (2, 70-71) encontram-se sáveis e lampreias em quantidade, mas só as trutas merecem o adjectivo «laudatissimas», muito louvadas, a que não será alheio serem dos peixes mais recomendados entre os médicos. Prolongam-se pelas margens os encómios ao rio, capaz de fertilizar os campos, onde abundam trigo, cevada, centeio, espelta, milho-miúdo e milho-painço. Do Vouga $(2,71-72)$ são saudadas as mesmas espécies piscícolas do Mondego, uma vez mais pela quantidade. 0 rio Douro $(2,72-76)$ apenas fica em segundo lugar perante 0 Minho pelo tamanho dos sáveis, lampreias e trutas; estas têm, contudo, a particularidade do sabor: «e trutas, preferidas pelos que, com razão, as consideram de sabor mais delicado». A apreciação de sabor mais delicado, «delicatioris gulae» não é mera subjectividade, dada a conexão entre sabor e salubridade. Por outro lado, a truta do Minho, mais pequena, seria aconselhada pelo Regimen sanitaits salernitanus, cujos versos citamos: "Si pisces molles sunt, magno corpore tolles, / Si pisces duri, parui plus ualituri: / [...] / Gornus plagitta, cum carpa, galbio truta». E agora em tradução: «Se os peixes são moles, com corpo os escolhes. Se os peixes são duros, são os pequenos mais seguros. / O gorno com a plagita o galbio e a truta». A lampreia, neste como nos passos anteriormente citados, é sempre valorizada pelo tamanho, pois a medicina, como tivemos oportunidade de verificar, considera-a nociva. Tolerava-se por ter bom sabor, mas era desa- conselhada por causar má digestão e gerar humores melancólicos, frios e secos. São João da Pesqueira consta no roteiro fluvial por proporcionar «enorme apanha de lampreias». Dos rios Brácaros (2, 76-77), usando a terminologia de Pompónio Mela (Pompónio: 3, 1, 10), o Ave, o Leça, o Neiva, o Minho e o Lima, refere-se o curso dos leitos, sem descrição piscícola, posto neles se darem as mesmas espécies que há no Minho (2,78): «De resto, todos estes rios e em primeiro lugar o próprio Minho são abundantes em peixes apreciados, lampreias, sáveis, trutas, trutas assalmonadas, trutas-mariscas e salmões». Da tradução da edição seguida, apenas substituímos trutas-arco-íris - «iridis» no original levaria a compreensível confusão - por trutas-mariscas, porque as primeiras foram introduzidas na Europa mais tarde, cerca de 1792, sendo oriundas das Américas, mas as mariscas, também com aspecto malhado, já existiam. O Lima $(2,78)$ merece um apontamento, «produz salmões e soilhos, ou seja asturjões, mas bastante pequenos». No original, lê-se «sed minores» por estarem a ser comparados com os do rio Minho, mas esta não é, em nossa opinião, uma forma de desmerecer, porque relativamente a determinados peixes de rio preferiam os médicos que se consumissem os de pequeno porte. Mas continuemos, agora com tradução nossa: «O Minho, por seu lado, tem-nos de grande tamanho e de excelente qualidade [praestantia]». Ou seja, sempre que os peixes não são apreciados pela quantidade, o tamanho é observado com 
perspicácia, mas, no caso destas espécies, ressalta o autor serem saudáveis. Eis a acepção que poderá ter «praestantia». Com efeito, um dos peixes de rocha mais elogiados na Antiguidade era o salmão, por perder «malitia» ao percorrer várias águas (salgada e doce). A última parte dedicada às descrições fluviais é denominada «Alguns outros rios» $(2,78-80)$. Apenas refere a fauna de dois, no primeiro caso por amor ao seu Alentejo: o Sor, no ponto onde se une ao Raia e toma o nome de rio Sorraia é onde «nós, Alentejanos, fazemos o célebre comércio de sáveis». Com o Ceira, que desagua no Mondego, termina, com a simples indicação de que este rio possui em abundância os mesmos peixes que o Mondego.

Concluímos por onde começámos, pela receita do sável. Pensamos que, após a nossa exposição e o nosso comentário ao levantamento, esta poderá ser agora mais compreensível à luz da teoria humoral. O sável, de que a saboga e a savelha constituem variedades, pertencia à 2. ${ }^{\text {a }}$ categoria de «bonitas», que compreendia todos os peixes de zonas costeiras. Era um peixe mais magro, «strigosius», e mais insípido do que o sável comum, posto a gordura ser um dos principais veículos de sabor dos alimentos. Se em Maio o peixe ganha um sabor agradável, gratia, é por ser a época do ano em que está mais gordo. Comê-lo acabado de pescar e optar por assá-lo enquadra-se, como atrás verificámos, nas prescrições da arte médica. O Autor distingue alimento que nutre de alimento medicamentoso, como eram con- siderados os «condimenta» (azeite, vinagre, sal e mel, mais tarde o açúcar) e os «aromata», as especiarias. 0 verbo «condio», vertido por adubar, remete para o molho sugerido para corrigir o temperamento frio da saboga, feito com pimenta, seca, como todas as especiarias, salsa e limão (em vez de vinagre). Aos saberes do humanista será justo acrescentar os de higiene.

\section{Bibliografia}

\section{Fontes}

Cardoso, F. R. (1602). Tractatus de sex rebus non naturalibus: nunc primum in lucem editus a doctore Ferdinando Roderico Cardoso in arte Appolinea quondam Conimbricae primario professore, nunc vero Regia Magestatis in regnis Lusitaniae Prothomedico dignissimo. Ad Philippum III Hispanium regem. (1. ${ }^{a}$ ed.) Ex Officina Georgii Rodriguez. Olyssipone;

Castro, A. A. de (1636). Doctoris Andreae Antonii de Castro Serenissimi Brigantiae Ducis, prothomedici et Orensis arcis praefecti maximi, De febrium curatione Libri tres. Quibus accessere duo libelli De simplicium medicamentorum facultatibus, et alter de qualitatibus alimentorum, quae humani corporis nutritioni sunt apta. Cum Indice rerum, et verborum scitu dignorum locupletissimo. Apud Emmanuelem Carvalho ducis typographum. Villaviçosae;

Fonseca, F. S. da (1626). Regimento para conservar a saúde e a vida, dividido em dois diálogo: o primeiro trata das seis cousas naõ naturais; o segundo das qualidades do ar, sítios e mantimentos do têrmo de Lisboa. (1. a ed.). [s.n.]. [s.l.]; Henriques, F. (1721). Anchora medicinal para conservar a vida com saúde. (1. ${ }^{a}$ ed.). Officina da Musica. Lisboa Occidental;

Lopes G. (1564). Commentarii de varia rei medicae lectione, Medicinæ Studiosis non parum utiles. Quorum Catalogum ab Epistola sequens pagella indicabit. (1. ${ }^{a}$ ed.). Apud Viduam Martini Nutii, Cum Gratia et Privilegio. Antuerpiae; 
Resende, A. (1533). Genethliacon. (1. ${ }^{a}$ ed.). [s.n.]. Bruxelas;

Resende, A. (2009). Antiguidades da Lusitânia. Portugaliae Monumenta Neolatina. Vol. 3. (Introd. trad. e comentário de R. M. Rosado Fernandes). Estabelecimento de texto por S. Tavares de Pinho. Imprensa da Universidade de Coimbra. Coimbra.

\section{Estudos}

Braga, I. D. (2015) Carne e Peixe: Uma Hierarquia de Consumos Alimentares. Em: I. D. Braga, e P. D. Braga (coord.). Animais e Companhias. Círculo de Lleitores. Lisboa;

Castro, I. O. (2018). Corpos, palatos e sensibilidade médica. Em: A. Cardoso, N. M. Proença, (coord.) Dor, sofrimento e saúde mental na Arquipatologia de Filipe Montalto. Húmus. Lisboa; Castro, I. O. (2011). Prática médica e alimentação nos textos portugueses seiscentistas. Em: P. F. da Costa e A. Cardoso (org.). Percursos na História do livro médico. Colibri. Lisboa;
Encarnação, J. (1991). da Invenção de Inscrições Romanas pelo Humanista André de Resende. Biblos, 67: 193-221;

Fernandes, R.M.R. (1984). Méthodologie et histoire dans De antiquitaibus Lusitaniae d'André de Resende. Actes du XXI Colloque International d'Études Humanistes L'Humanisme et L'Europe U F.C.G./Centre Culturel Portugais. Paris: pp. 487-505;

Newman, L. F. (1946). Some notes on foods and dietetics in the sixteenth and seventeenth centuries. The Journal of the Royal Anthropological Institute of Great Britain and Ireland, 76, 1: 39-49;

Nutton, V. (2004). Ancient Medicine. Routledge. London and New York.

Pereira, M. H. R. (1973). Obras Médicas de Pedro Hispano. Universidade de Coimbra. Coimbra;

Pina, L. (1965). A fauna marítima e fluvial na alimentação portuguesa do século XVIII. Revista de Etnografia. Imprensa Portuguesa. Museu de Etnografia e História, 9, vol. 5, t. 1: 5-42;

Waquet, F. (1988). Le latin ou l'empire d'un signe: $\mathrm{XVl} \mathrm{e}^{\mathrm{e}}-\mathrm{XX}$ siècle. Albin Michel. Paris. 